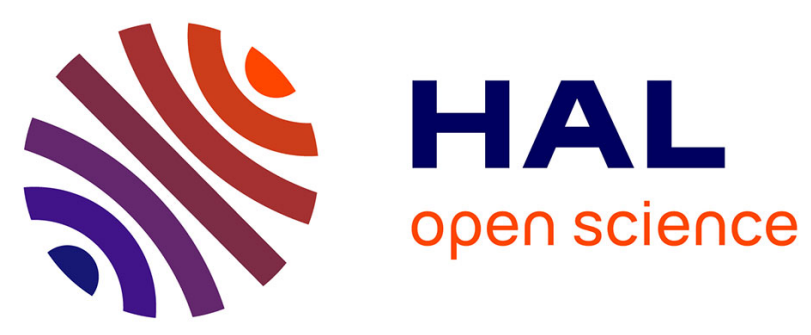

\title{
The key process parameters influencing formation of columnar microstructure in suspension plasma sprayed zirconia coatings
}

Pawel Sokolowski, Stefan Kozerski, Lech Pawlowski, Andrzej Ambroziak

\section{- To cite this version:}

Pawel Sokolowski, Stefan Kozerski, Lech Pawlowski, Andrzej Ambroziak. The key process parameters influencing formation of columnar microstructure in suspension plasma sprayed zirconia coatings . Surface and Coatings Technology, 2014, 260, pp.97-106. 10.1016/j.surfcoat.2014.08.078 . hal01102637

\section{HAL Id: hal-01102637 \\ https://hal-unilim.archives-ouvertes.fr/hal-01102637}

Submitted on 13 Jan 2015

HAL is a multi-disciplinary open access archive for the deposit and dissemination of scientific research documents, whether they are published or not. The documents may come from teaching and research institutions in France or abroad, or from public or private research centers.
L'archive ouverte pluridisciplinaire HAL, est destinée au dépôt et à la diffusion de documents scientifiques de niveau recherche, publiés ou non, émanant des établissements d'enseignement et de recherche français ou étrangers, des laboratoires publics ou privés. 


\title{
The key process parameters influencing formation of columnar microstructure in suspension plasma sprayed zirconia coatings $s^{\text {is }}$
}

\author{
Paweł Sokołowski ${ }^{\mathrm{a}, \mathrm{b}}$, Stefan Kozerski ${ }^{\mathrm{b}}$, Lech Pawłowski ${ }^{\mathrm{a}, *}$, Andrzej Ambroziak ${ }^{\mathrm{b}}$ \\ a SPCTS, UMR CNRS 7315, University of Limoges, 12, rue Atlantis, 87068 Limoges, France \\ ${ }^{\mathrm{b}}$ Faculty of Mechanics, Wrocław University of Technology, ul. Łukasiewicza 5, 50-371 Wrocław, Poland
}

\section{A R T I C L E I N F O}

Available online 21 September 2014

\section{Keywords:}

Thermal barrier coatings

Suspension plasma spraying

Yttria stabilized zirconia

Ceria stabilized zirconia

Columnar microstructure of coatings

\begin{abstract}
A B S T R A C T
The paper discusses the screening of experimental variables leading to formation of a columnar microstructure in suspension plasma sprayed zirconia coatings. These variables tested in 12 experimental runs included: (i) 2 types of zirconia powder; (ii) 4 concentration of solids in suspensions; (iii) 4 substrate preparation methods; and (iv) 2 plasma spray setups. Two different, commercially available, powders were used to formulate the suspensions. Yttria and ceria stabilized zirconia of composition $\mathrm{ZrO}_{2}+24$ wt.\% $\mathrm{CeO}_{2}+2.5$ wt.\% $\mathrm{Y}_{2} \mathrm{O}_{3}$ (YCSZ) was milled the decrease the particles sizes. The yttria stabilized zirconia of composition $\mathrm{ZrO}_{2}+14$ wt.\% $\mathrm{Y}_{2} \mathrm{O}_{3}$ (14YSZ) was used as received. The coatings were deposited on $304 \mathrm{~L}$ stainless steel substrates which had the surface prepared by: (i) grid blasting; (ii) grinding; (iii) turning; and (iv) laser treatment. The 3D topographies of substrates' surfaces were characterized and their roughnesses were measured. The suspensions were plasma sprayed using the following plasma torches: SG-100 of Praixair and Triplex of Sulzer-Metco. The microstructure of powders and coatings was analyzed by optical microscopy, scanning electron microscopy (SEM) and field emission scanning electron microscopy (FE-SEM) as well as by X-ray diffraction. The columnar microstructure was formed in coatings sprayed with both plasma setups sprayed using finer 14YSZ powder suspensions. The substrate surface preparation as well as low concentration of solids in suspension promoted their formation. Rietveld method was applied to determine the quantity of different phases in the structure of coatings and to calculate the lattice parameters. The YCSZ coatings crystallized in mainly tetragonal phase with a small content of monoclinic phase. The 14YSZ crystallized in cubic phase. Finally, the thermal diffusivity of coatings was characterized up to $523 \mathrm{~K}$ with the use of laser flash method and thermal conductivities of coatings were determined. The conductivities were in the range from 0.6 to $1.1 \mathrm{~W} /(\mathrm{mK})$ depending on temperature for YCSZ and 14YSZ coatings.
\end{abstract}

(c) 2014 Elsevier B.V. All rights reserved.

\section{Introduction}

The microstructure of suspension plasma sprayed coatings results from the particularities of process such as e.g. liquid feedstock which includes small, nano- or submicrometric solids and, on the other hand, from a very short spray distance. Typically, the coatings contain large lamellas formed from the solids agglomerated in-flight and small grains which remained at the periphery of plasma jet and form a two-zone microstructure [1]. The small grains may sinter due to the heat flux coming from plasma torch [2]. The coatings contain also usually a network of fine pores which may reduce their thermal conductivity [3-5]. Low thermal conductivity is an important advantage in the application of stabilized zirconia as thermal barrier coatings (TBC). The TBCs must

\footnotetext{
is The paper was presented on 41 International Conference on Metallurgical Coatings \& Thin Films, April 28-May 2, 2014, San Diego, CA, USA.

* Corresponding author. Tel.: + 33587202412.

E-mail address: lech.pawlowski@unilim.fr (L. Pawłowski).
}

however withstand many thermal shocks in service and the best adapted microstructure to achieve this specification is a columnar one in which crystal grains grow up perpendicularly to the interface. Such microstructure is formed in the films condensed from saturated vapors e.g. in the process called electron beam physical vapor deposition (EBPVD) which is described in many references [6-8]. An important drawback of EBPVD processes is a capital cost of coatings' equipment being many times greater than that of suspension plasma spraying (SPS) equipment. This difference in the capital cost was one of the motivations to realize the research on the columnar structure in stabilized zirconia coatings using SPS processes. The studies initiated a few years ago focused on: (i) relationship between suspension formulation and the microstructure of YSZ coatings obtained by SPS [9]; (ii) the effect of rare-earth additives on thermal transport properties of zirconia coatings [10]; and more recently (iii), the formation of columnar structure in suspension plasma sprayed $\mathrm{Mg}-\mathrm{Al}-$ spinel coatings [11]. The present study focuses on screening of key process parameters favorable to form the columnar microstructure. Consequently, the SPS zirconia coatings were suspension sprayed using different initial powders including yttria and ceria as zirconia main stabilizers with two different plasma 
spray setups. Moreover, the suspensions were formulated using 4 different solid phase concentrations ranging from 2.5 to $20 \mathrm{wt}$.\% of solid. Finally, the coatings were sprayed onto substrates having surfaces of different morphology. Basing onto the analysis of obtained results, a simplified description of the mechanism of columns formation was made.

\section{Experimental methods}

\subsection{Suspension formulation}

The first of used powder was Metco 205NS having composition $\mathrm{ZrO}_{2}$ +24 wt. $\% \mathrm{CeO}_{2}+2.5$ wt. $\% \mathrm{Y}_{2} \mathrm{O}_{3}$ (YCSZ). The granulometric tests of the powder use the laser diffraction setup of type LA-950V2 of Horiba (Kyoto, Japan). The volume mean diameters of the initial coarse powder were equal to $d_{\mathrm{v} 50}=39.6 \mu \mathrm{m}$. The morphology of the powder, characterized using SEM type Philips XL30 (Eindhoven Netherlands), is presented in Fig. 1a. The initial powder was milled up using the MoliNEx setup of Netzsch (Selb, Germany) using zirconia balls having a $2 \mathrm{~mm}$ diameter, ethanol as cooling medium and Beycostat C123 as dispersant. The mean diameter of powder particles decreased down to $d_{\mathrm{v} 50}=$ $696 \mathrm{~nm}$ and the milled powder morphology is shown in Fig. 1b. The second used powder was yttria stabilized zirconia powder, $\mathrm{ZrO}_{2}+14 \mathrm{wt}$.\% $\mathrm{Y}_{2} \mathrm{O}_{3}$ (14YSZ) of Tosoh (Tokyo, Japan). The mean diameter was equal to

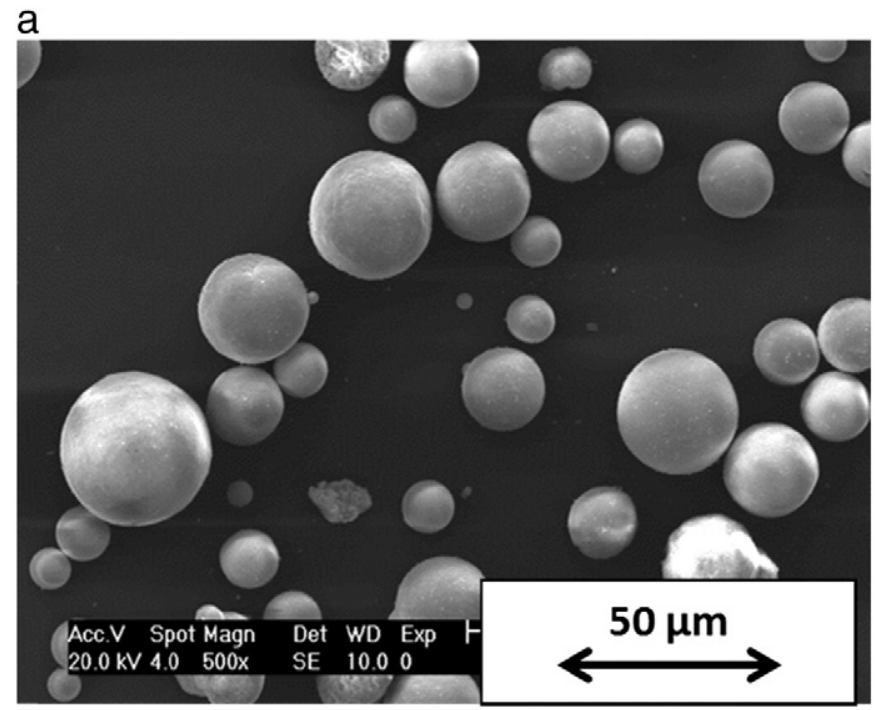

b

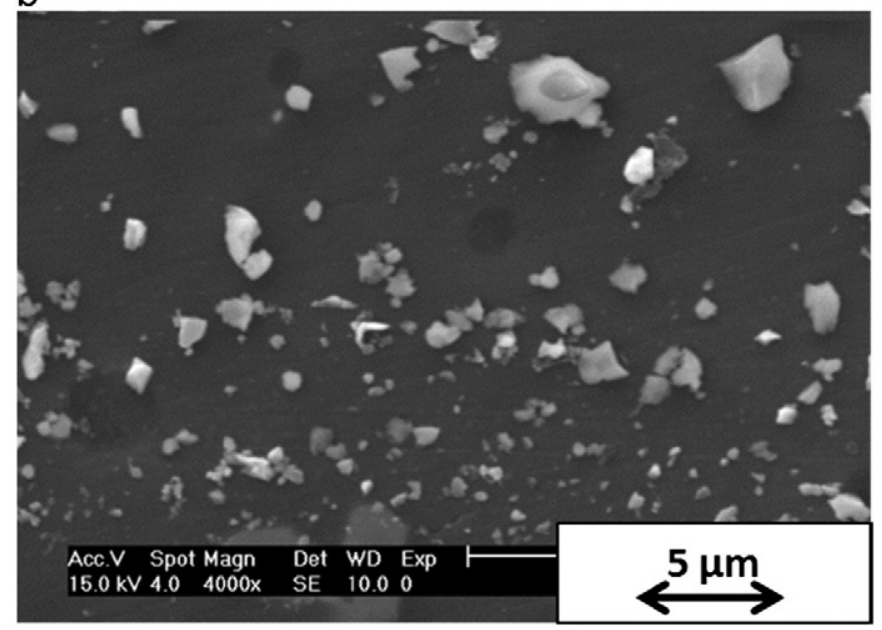

Fig. 1. SEM micrographs (secondary electrons) of 205NS Metco powder: (a)-initial powder; (b)-powder after milling (b).
$d_{\mathrm{V} 50}=398 \mathrm{~nm}$ and its morphology observed using FE-SEM of JSM-7400F of Jeol (Tokyo, Japan) is shown in Fig. 2. The XRD phase analysis made using Bruker D8 Advance setup (Billerica, MA, USA) enabled to find out that $14 \mathrm{YSZ}$ powder crystallized as yttrium zirconium oxide identified using file no. 01-078-5501 of the JCPDS database. The phase composition of YCSZ powder enabled to find three different phases identified with the help of the JCPDS database:

- tetragonal phase of cerium yttrium zirconium oxide identified using file no. 04-013-9723;

- monoclinic phase of $\mathrm{ZrO}_{2}$-Baddeleyite identified using file no. 00-0371484;

- cubic phase of cerium yttrium oxide identified using file no. 04-0164629.

The suspensions of water and ethanol in ratio $1: 1$ with different content of solid phase were prepared, in wt.\%: $2.5 ; 5 ; 10$; and 20. The dispersant agent was added to suspension to prevent the agglomeration and sedimentation. The zeta potential measurements enabled to find the values of $\zeta=82.5 \mathrm{mV}$ for the suspension with 14YSZ powder (the suspension had $\mathrm{pH}=4.8$ ) and $\zeta=-12.9 \mathrm{mV}$ for YCSZ powder suspension $(\mathrm{pH}=6.8)$.

\subsection{Substrate preparation}

Stainless steel 304L discs of diameter 25 and thicknesses of 10 or of $2 \mathrm{~mm}$ were used as substrates. The substrates' surfaces were prepared using: (i) grid blasting; (ii) grinding; (iii) turning; and (iv) laser treatment. White corundum with the particles size ranging between 500 and $600 \mu \mathrm{m}$ was used for grid blasting of substrates. Grinding was performed with the use of SiC abrasive paper (grit size 320). The laser treatment was realized using Duetto picosecond laser of Time-Bandwidth Products (Zürich, Switzerland). The substrates were cleaned up in the ultrasonic bath of ethanol prior to spraying. The 3D views of substrates topographies were made confocal microscope type Lext OLS4000 of OLYMPUS (Tokyo, Japan) and are presented in Fig. 3. Finally, the roughness of the substrate surfaces was measured with the use of the profilometer type Form Talysurf 120L of Rank Taylor Hobson (Leicester, England) and the results were as follows:

- grid-blasting: $R_{\mathrm{a}}=5.50 \mu \mathrm{m}, R_{\mathrm{z}}=32.4 \mu \mathrm{m}$;

- grinding: $R_{\mathrm{a}}=0.07 \mu \mathrm{m}, R_{\mathrm{z}}=0.6 \mu \mathrm{m}$;

- laser treatment: $R_{\mathrm{a}}=3.6 \mu \mathrm{m}, R_{\mathrm{z}}=17.6 \mu \mathrm{m}$;

- turning: $R_{\mathrm{a}}=0.54 \mu \mathrm{m}, R_{\mathrm{z}}=3.06 \mu \mathrm{m}$.

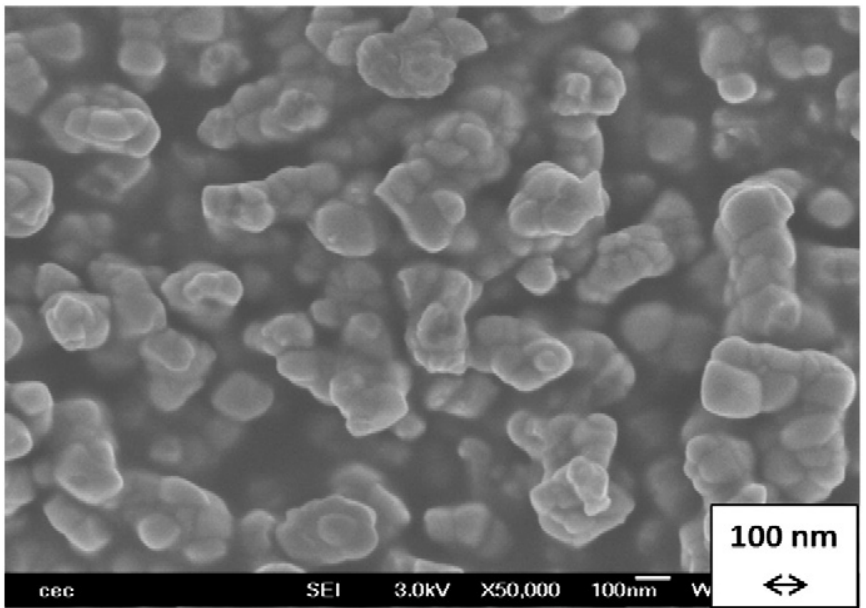

Fig. 2. FE-SEM micrograph (secondary electrons) of Tosoh powder 

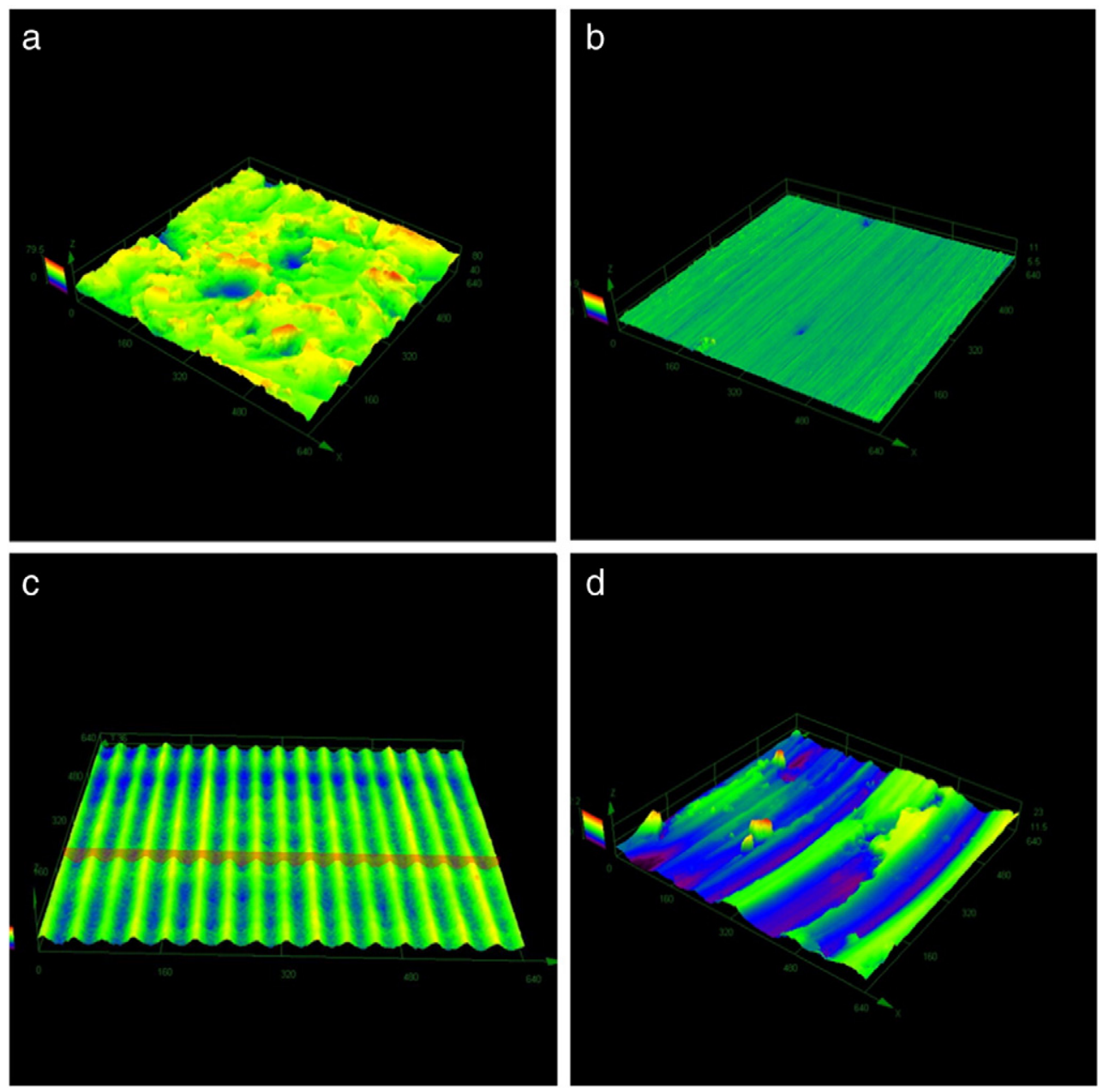

Fig. 3. Topography of substrates used to deposit coatings: (a)-grid-blasted; (b)-grinded, (c)-laser treated; (d)-turned.

\subsection{Plasma spraying}

The coatings were plasma sprayed using two spray installations. The first one included the torch SG-100 of Praxair (Indianapolis, IN, USA) with an internal injector, mounted on a 5-axis robot as described in details elsewhere [3]. The second installation used was equipped in threecathode Triplex torch of Sulzer Metco (Wohlen, Switzerland). The temperature of coatings at spraying was controlled using a pyrometer IN 5 Plus of LumaSense Technologies (Santa Clara, CA, USA). The operational spray parameters are collected in Table 1 . The spray experiments were designed with the use of the following variables: (i) powder type; (ii) concentration of solid in suspension; and (iii) substrates' surface preparation. The detailed design is shown in Table 2.

\subsection{Coating characterizations}

The thickness of the coatings was estimated using metallographic cross-sections of samples observed with optical microscope Eclipse LV100 of Nikon (Tokyo, Japan). The mean thickness of the coatings was found from 18 measurements in different regions of the coatings. The procedure of this measurement was as follows: 3 regions were chosen for and in each sample and 6 local thicknesses were measured in each region. Finally, a mean value was calculated. The porosity was estimated with the use of software Image J. The morphology of the coating surface and sections were observed using SEM XL 30 and the phase analysis was made using Bruker D8 diffractometer using CuK $\alpha 1$ radiation in the range of $2 \theta$ angles from $15^{\circ}$ to $120^{\circ}$. The phases were identified using Diffrac + Eva software. The quantitative analysis of coatings was carried out by the Rietveld method with the use of Topas V4.1 software.

Table 1

Operational spray parameters.

\begin{tabular}{|c|c|c|}
\hline Process parameters & Torch SG-100 of Praxair & $\begin{array}{l}\text { Torch Triplex of } \\
\text { Sulzer-Metco }\end{array}$ \\
\hline Electric power, kW & 40 & 45 \\
\hline Working gases composition & $\mathrm{Ar}+\mathrm{H}_{2}$ & $\mathrm{Ar}$ \\
\hline $\begin{array}{l}\text { Working gases flow } \\
\text { rate, slpm }\end{array}$ & $45+5$ & 70 \\
\hline Spray distance, $\mathrm{mm}$ & 40 & 70 \\
\hline Torch speed velocity, $\mathrm{mm} / \mathrm{s}$ & 500 & 1000 \\
\hline Number of scans & $\begin{array}{l}\text { Depends on experimental } \\
\text { run. After each scan the } \\
\text { spraying was interrupted } \\
\text { until temperature } \\
\text { dropped down to } 40{ }^{\circ} \mathrm{C}\end{array}$ & $\begin{array}{l}\text { Depends on } \\
\text { experimental run. When } \\
\text { coating's temperature } \\
\text { reached } 500{ }^{\circ} \mathrm{C} \text { the } \\
\text { spraying was } \\
\text { interrupted until } \\
\text { temperature dropped } \\
\text { down to } 150{ }^{\circ} \mathrm{C}\end{array}$ \\
\hline $\begin{array}{l}\text { Distance between the } \\
\text { neighboring torch } \\
\text { passes, mm }\end{array}$ & 3 & 10 \\
\hline Suspension injector type & Nozzle inside the torch & Nozzle outside the torch \\
\hline $\begin{array}{l}\text { Nozzle injector internal } \\
\text { diameter, mm }\end{array}$ & 0.50 & 0.15 \\
\hline $\begin{array}{l}\text { Static pressure in suspension } \\
\text { container, } \mathrm{MPa}\end{array}$ & 0.05 & 1.3 \\
\hline
\end{tabular}


Table 2

Design of spray experiments and thickness and porosity of coatings.

\begin{tabular}{|c|c|c|c|c|c|c|c|}
\hline Run no. & Powder material & Sample description & $\begin{array}{l}\text { Concentration of solid } \\
\text { in suspension [wt.\%] }\end{array}$ & Type of plasma torch & Substrate preparation & $\begin{array}{l}\text { Thickness, average; } \\
\text { standard deviation, } \mu \mathrm{m}\end{array}$ & $\begin{array}{l}\text { Porosity average and } \\
\text { standard deviation, \% }\end{array}$ \\
\hline \multirow[t]{3}{*}{1} & $14 Y S Z$ & ST21 & 2.5 & SG-100 & Grit-blasting & & \\
\hline & $14 Y S Z$ & ST22 & 2.5 & SG-100 & Laser treatment & $66 ; 4$ & $21.4 ; 2.7$ \\
\hline & $14 Y S Z$ & ST23 & 2.5 & SG-100 & Grinding & & \\
\hline \multirow[t]{3}{*}{2} & $14 Y S Z$ & ST51 & 5 & SG-100 & Grit-blasting & & \\
\hline & $14 Y S Z$ & ST52 & 5 & SG-100 & Laser treatment & $83 ; 9$ & $18.3 ; 2.3$ \\
\hline & $14 Y S Z$ & ST53 & 5 & SG-100 & Grinding & & \\
\hline \multirow[t]{3}{*}{3} & $14 Y S Z$ & ST101 & 10 & SG-100 & Grit-blasting & & \\
\hline & $14 Y S Z$ & ST102 & 10 & SG-100 & Laser treatment & $116 ; 14$ & $15.2 ; 1.4$ \\
\hline & $14 Y S Z$ & ST103 & 10 & SG-100 & Grinding & & \\
\hline \multirow[t]{3}{*}{4} & YCSZ & SC21 & 2.5 & SG-100 & Grit-blasting & & \\
\hline & YCSZ & SC22 & 2.5 & SG-100 & Turned & $55 ; 3$ & $19.0 ; 2.2$ \\
\hline & YCSZ & SC23 & 2.5 & SG-100 & Grinding & & \\
\hline \multirow[t]{3}{*}{5} & YCSZ & SC51 & 5 & SG-100 & Grit-blasting & & \\
\hline & YCSZ & SC52 & 5 & SG-100 & Turned & $105 ; 4$ & $15.5 ; 1.5$ \\
\hline & YCSZ & SC53 & 5 & SG-100 & Grinding & & \\
\hline \multirow[t]{3}{*}{6} & YCSZ & SC101 & 10 & SG-100 & Grit-blasting & & \\
\hline & YCSZ & SC102 & 10 & SG-100 & Turned & $96 ; 7$ & $13.2 ; 0.9$ \\
\hline & YCSZ & SC103 & 10 & SG-100 & Grinding & & \\
\hline \multirow[t]{3}{*}{7} & $14 Y S Z$ & TT51 & 5 & Triplex & Grit-blasting & & \\
\hline & $14 Y S Z$ & TT52 & 5 & Triplex & Laser treatment & $80 ; 5$ & $16.0 ; 1.0$ \\
\hline & $14 Y S Z$ & TT53 & 5 & Triplex & Grinding & & \\
\hline \multirow[t]{3}{*}{8} & $14 Y S Z$ & TT101 & 10 & Triplex & Grit-blasting & & \\
\hline & $14 Y S Z$ & TT102 & 10 & Triplex & Laser treatment & $77 ; 2$ & $13.1 ; 0.8$ \\
\hline & $14 Y S Z$ & TT103 & 10 & Triplex & Grinding & & \\
\hline \multirow[t]{3}{*}{9} & $14 Y S Z$ & TT201 & 20 & Triplex & Grit-blasting & & \\
\hline & $14 Y S Z$ & TT202 & 20 & Triplex & Laser treatment & $91 ; 2$ & $11.8 ; 0.9$ \\
\hline & $14 Y S Z$ & TT203 & 20 & Triplex & Grinding & & \\
\hline \multirow[t]{3}{*}{10} & YCSZ & TC51 & 5 & Triplex & Grit-blasting & & \\
\hline & YCSZ & TC52 & 5 & Triplex & Turned & $74 ; 2$ & $18.0 ; 2.2$ \\
\hline & YCSZ & TC53 & 5 & Triplex & Grinded & & \\
\hline \multirow[t]{3}{*}{11} & YCSZ & TC101 & 10 & Triplex & Grit-blasting & & \\
\hline & YCSZ & TC102 & 10 & Triplex & Turned & $91 ; 2$ & $15.9 ; 1.6$ \\
\hline & YCSZ & TC103 & 10 & Triplex & Grinded & & \\
\hline \multirow[t]{3}{*}{12} & YCSZ & TC201 & 20 & Triplex & Grit-blasting & & \\
\hline & YCSZ & TC202 & 20 & Triplex & Turned & $148 ; 7$ & $12.4 ; 1.2$ \\
\hline & YCSZ & TC203 & 20 & Triplex & Grinded & & \\
\hline
\end{tabular}

Finally, thermal diffusivity of 14YSZ and YCSZ coatings was measured by laser flash technique using setup LFA 447 of Netzsch (Selb, Germany). Both sides of samples were coated with graphite prior to the measurements in order to provide better absorption and emission of radiative energy. The measurements were made in the temperature range between room temperature (RT) to $523 \mathrm{~K}$. The measurements were made with the use of the coatings sprayed on the grit-blasted substrates and the 2-layer model was developed to determine thermal diffusivity of the coatings. The corrections resulting from: (i) heat losses; (ii) pulse duration, and (iii) contact resistance were included in the model used for calculations. To calculate the thermal diffusivity of ceramic coatings, it was necessary to know the values of their thicknesses as well as the thermal diffusivity values of the steel. Such material data as density in RT, as well as thermal dilatation and specific heat in all temperatures used in measurements had to be known for substrate (stainless steel 304L) and ceramic coatings. The porosity of ceramic coatings, $P$, was used to correct the density following the expression:

$\rho_{300}=\rho_{0} \cdot(1-\mathrm{P})$

where $\rho_{0}$ is density in RT being equal to $6050 \mathrm{~kg} / \mathrm{m}^{3}$ for dense tetragonal phase of $\mathrm{ZrO}_{2}$ and to $5830 \mathrm{~kg} / \mathrm{m}^{3}$ for dense cubic phase of $\mathrm{ZrO}_{2}[12,13]$. The specific heat, $c_{\mathrm{p}}(\mathrm{T})$, and thermal dilatation values, $\frac{\Delta L}{L}(T)$, were taken from literature separately for tetragonal and cubic $\mathrm{ZrO}_{2}$ [14-16], which were the main phases in YSZ and YCSZ coatings (according to XRD analysis of phase composition of coatings). The values of specific heat for alloys or composites were recalculated from Kopp-Neumann law. Finally, the data for calculating thermal diffusivity of coatings are collected in Table 3. The values of specific heat, thermal dilatation and thermal diffusivity of stainless steel substrate were taken from literature [17-19].
Thermal diffusivity of stainless steel 304L was also measured directly using our experimental setup. Knowing thermal diffusivity values, $a(\mathrm{~T})$, thermal conductivity, $\lambda(\mathrm{T})$ was calculated following the equation:

$\lambda(T)=a(T) \cdot c_{p}(T) \cdot \frac{\rho_{300}}{1+3 \cdot \frac{\Delta L}{L}(T)}$

\section{Results}

\subsection{Microstructural characterization}

The phase analysis in the coatings sprayed using 14 YSZ powder indicates only cubic zirconia (Fig. 4a). This phase remains unchanged at

Table 3

Thermal dilatation and specific heat values used in calculations of thermal diffusivity of 14YSZ and YCSZ coatings [14-16].

\begin{tabular}{|c|c|c|c|c|}
\hline \multirow{2}{*}{$\begin{array}{l}\text { Temperature } \\
{[\mathrm{K}]}\end{array}$} & \multicolumn{2}{|l|}{$14 Y S Z$} & \multicolumn{2}{|l|}{ YCSZ } \\
\hline & $\begin{array}{l}\text { Specific heat } \\
c_{\mathrm{p}} \\
{[\mathrm{J} /(\mathrm{kg} \mathrm{K})]}\end{array}$ & $\begin{array}{l}\text { Thermal } \\
\text { dilatation } \\
\frac{\Delta L}{L}[-]\end{array}$ & $\begin{array}{l}\text { Specific heat } \\
c_{\mathrm{p}} \\
{[\mathrm{J} /(\mathrm{kg} \mathrm{K})]}\end{array}$ & $\begin{array}{l}\text { Thermal } \\
\text { dilatation } \\
\frac{\Delta L}{L}[-]\end{array}$ \\
\hline 298 & 515 & $8.5267 \times 10^{-5}$ & 427 & $3.4031 \times 10^{-5}$ \\
\hline 323 & 540 & $2.5646 \times 10^{-4}$ & 441 & $2.0583 \times 10^{-4}$ \\
\hline 373 & 580 & $6.8840 \times 10^{-4}$ & 465 & $5.5722 \times 10^{-4}$ \\
\hline 423 & 610 & $1.1262 \times 10^{-3}$ & 485 & $9.1804 \times 10^{-4}$ \\
\hline 473 & 630 & $1.6598 \times 10^{-3}$ & 501 & $1.2873 \times 10^{-3}$ \\
\hline 523 & 655 & $2.0206 \times 10^{-3}$ & 514 & $1.6640 \times 10^{-3}$ \\
\hline
\end{tabular}


coating deposition. The YCSZ coatings were modified at spraying and the cubic phase present in initial powder was not detected in obtained coatings (Fig. 4b). The Rietveld analysis shows the lattice parameters of phases obtained in all experimental runs (Table 4).

\subsubsection{Morphology of coating suspension formulated using 14YSZ powder}

3.1.1.1. Torch SG-100. The coatings had a two-zone-microstructure with large molten lamellas and fine unmolten particles. The morphologies of coatings sprayed using suspension having a concentration of 2.5 wt.\% of solid are shown in Fig. 5. The coatings sprayed have a columnar microstructure for all type of substrate surface preparation even including polished substrate (see Fig. 5c). The columnar structure is visible also for the suspension of greater i.e. $5 \mathrm{wt} . \%$ concentration (Fig. 6); however, the columns are much less visible while grinded substrate was used. Finally, the increase of suspension concentration up to $10 \mathrm{wt}$ \% resulted in formation of the columnar microstructure only in coatings sprayed onto the laser treated surface (Fig. $7 \mathrm{~b}$ ). The porosity of coatings decreases from about $21 \%$ at lowest suspension concentration of $2.5 \mathrm{wt}$.\% down to about $15 \%$ at the suspension concentration of 10 wt.\% (see Table 2).

3.1.1.2. Torch Triplex. The coatings sprayed using suspension having 10 wt.\% of solid phase were generally dense and the columnar microstructure is visible only for the laser treated substrate (Fig. 8b). The coatings sprayed using $20 \mathrm{wt}$.\% suspension did not indicate any columnar
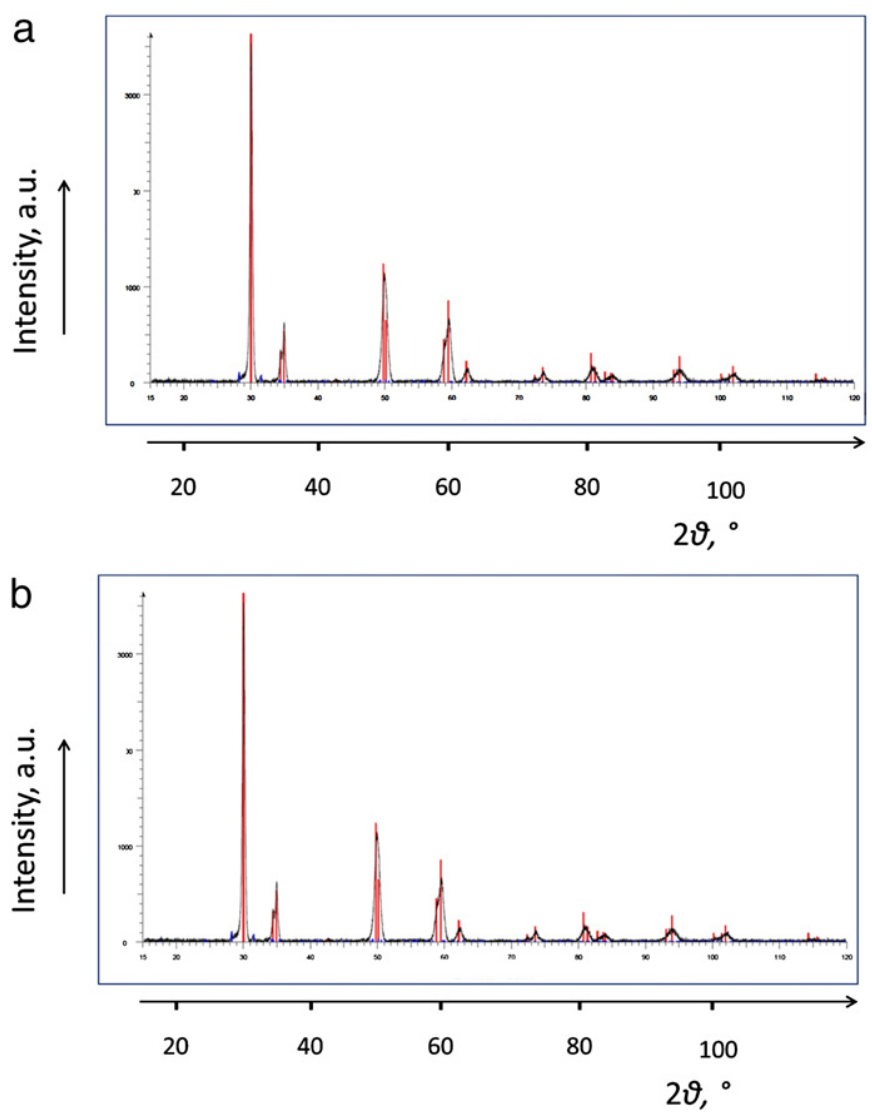

Fig. 4. X-ray diffraction diagram of typical coating sprayed using: (a) sample TT102 obtained using 14YSZ powder suspension containing cubic zirconia identified using 00-030-1468 1484 file of the JCPDS data base; (b) sample TC202 obtained using YCSZ powder containing suspension tetragonal and monoclinic zirconia identified using 04-013-9723 and 04-004-4339 files of the JCPDS data base. structure. The porosity of the coatings is lower than that sprayed using SG-100 torch and decreases from about $16 \%$ to about $12 \%$ with increasing suspension concentration.

\subsubsection{Morphology of coating suspension formulated using YCSZ powder}

The application of suspension with the use of coarse YCSZ powder resulted in coatings which do not have a columnar structure independent on suspension concentration and torch type. The examples of microstructures obtained with torch SG-100 and Triplex are shown in Figs. 9 and 10 respectively. The increase in suspension concentration results in the increase in coating density and in fewer defects and fewer pores (see Fig. 10). The coating porosity is lower for coatings sprayed using suspension formulated using YCSZ powder than that formulated using $14 \mathrm{YSZ}$ one and for that sprayed using Triplex torch than that sprayed using SG-100 one (see Table 2). Consequently, the lowest porosity of about $12 \%$ was reached for coatings sprayed using suspension of concentration $20 \mathrm{wt} . \%$, YCSZ powder and Triplex torch.

\subsection{Thermal conductivity of sprayed coatings}

The thermal conductivity of coatings sprayed using suspension formulated using fine 14YSZ powder is shown in Fig. 11a. The conductivity is lower for the coatings sprayed using SG-100 torch than that sprayed using Triplex one and decreases with concentration of solid in suspension. Similar observations can be made for the coatings made using suspension formulated using YCSZ powder. Finally, the thermal conductivity of coatings sprayed using suspension including 14YSZ powder is slightly lower than that sprayed using YCSZ powder suspension for similar suspension concentrations.

\section{Discussion}

The thermal conductivity of tested samples was determined to be in the range of 0.6 to $1.1 \mathrm{~W} /(\mathrm{mK})$. The lowest conductivity values were obtained for the samples sprayed using well stabilized suspension having small concentration of 14YSZ powder using SG-100 torch obtained in the spray run ST22 (Fig. 11a). Similar conductivity values were obtained for YCSZ sprayed using Triplex torch in spray run TC52 (see Fig. 11b). The conductivity values are comparable to those obtained for the suspension sprayed 8YSZ described elsewhere [3]. The low values of conductivity results from: (i) high porosity of coatings and, in particular, from the presence of fine pores; (ii) bad contacts between the grains; and (iii) from the presence of small, unmolten grains being sintered with the other and discussed elsewhere [1,2].

The columnar microstructure was formed in the samples: ST22, ST23, ST52, ST102, and TT102. All the samples were sprayed using 14 YSZ powder being a finer one. Consequently, only fine powder formulated suspension enabled formation of the columnar microstructure independent of the torch used. The substrate surface preparations methods resulting in the formation of the columnar microstructure are as follows:

- laser treated substrate coated with the help of the SG-100 torch (ST22 and ST52 shown in Figs. 5b and 6b respectively) and with the help of the Triplex torch (sample TT102 shown in Fig. 8b);

- machined substrate sprayed using 14YSZ suspension with the SG-100 torch (sample ST102 shown in Fig. 7b);

- grinded substrate coated with the help of the SG-100 torch (sample 23 shown in Fig. 5c).

Finally, low concentration of fine solids in suspension promoted the formation of the columnar microstructure. The greatest concentration among the tested ones resulting in such microstructure was $10 \mathrm{wt} . \%$ of solids suspension sprayed onto the laser treated substrate. The obtained experimental results enable a design of a simplified a mechanism of formation of the columnar microstructure. 
Table 4

Rietveld analyses of phase's content and lattice parameters in coatings sprayed in all experimental runs.

\begin{tabular}{|c|c|c|c|c|c|c|c|c|c|}
\hline \multicolumn{7}{|c|}{ YCSZ coatings } & \multicolumn{3}{|c|}{ 14YSZ coatings } \\
\hline \multirow[t]{2}{*}{ Sample } & \multicolumn{3}{|c|}{ Tetragonal phase } & \multicolumn{3}{|c|}{ Monoclinic phase } & \multirow[t]{2}{*}{ Sample } & \multicolumn{2}{|l|}{ Cubic phase } \\
\hline & Content, wt.\% & $a, \AA$ & $c, \AA$ & Content, wt.\% & $a, b, \AA$ & $c, \AA ; \gamma,{ }^{\circ}$ & & Content, wt.\% & $a, \AA$ \\
\hline SC22 & 97.45 & 3.6401 & 5.2133 & 2.55 & $\begin{array}{l}5.1570 \\
5.2601\end{array}$ & $\begin{array}{l}5.2590 \\
99.165\end{array}$ & ST22 & 100 & 5.1404 \\
\hline SC52 & 97.10 & 3.6406 & 5.2160 & 2.90 & $\begin{array}{l}5.1532 \\
5.2719\end{array}$ & $\begin{array}{l}5.2551 \\
99.064\end{array}$ & ST52 & 100 & 5.1409 \\
\hline SC102 & 97.30 & 3.6382 & 5.2097 & 2.70 & $\begin{array}{l}5.1535 \\
5.2545\end{array}$ & $\begin{array}{l}5.2574 \\
99.090\end{array}$ & ST102 & 100 & 5.1410 \\
\hline TC52 & 92.62 & 3.6351 & 5.2167 & 7.38 & $\begin{array}{l}5.1884 \\
5.2783\end{array}$ & $\begin{array}{l}5.2077 \\
98.799\end{array}$ & TT52 & 100 & 5.1413 \\
\hline TC102 & 96.02 & 3.6358 & 5.2146 & 3.98 & $\begin{array}{l}5.1867 \\
5.2983\end{array}$ & $\begin{array}{l}5.2033 \\
98.834\end{array}$ & TT102 & 100 & 5.1427 \\
\hline TC202 & 94.54 & 3.6353 & 5.2161 & 5.46 & $\begin{array}{l}5.1932 \\
5.2993\end{array}$ & $\begin{array}{l}5.2046 \\
98.818\end{array}$ & TT202 & 100 & 5.1434 \\
\hline
\end{tabular}


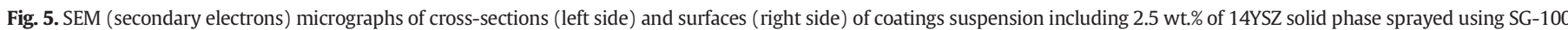
torch onto substrates prepared by: (a)-sand blasting, sample ST21; (b)-laser treatment, sample ST22; (c) -grinding, sample ST23. 

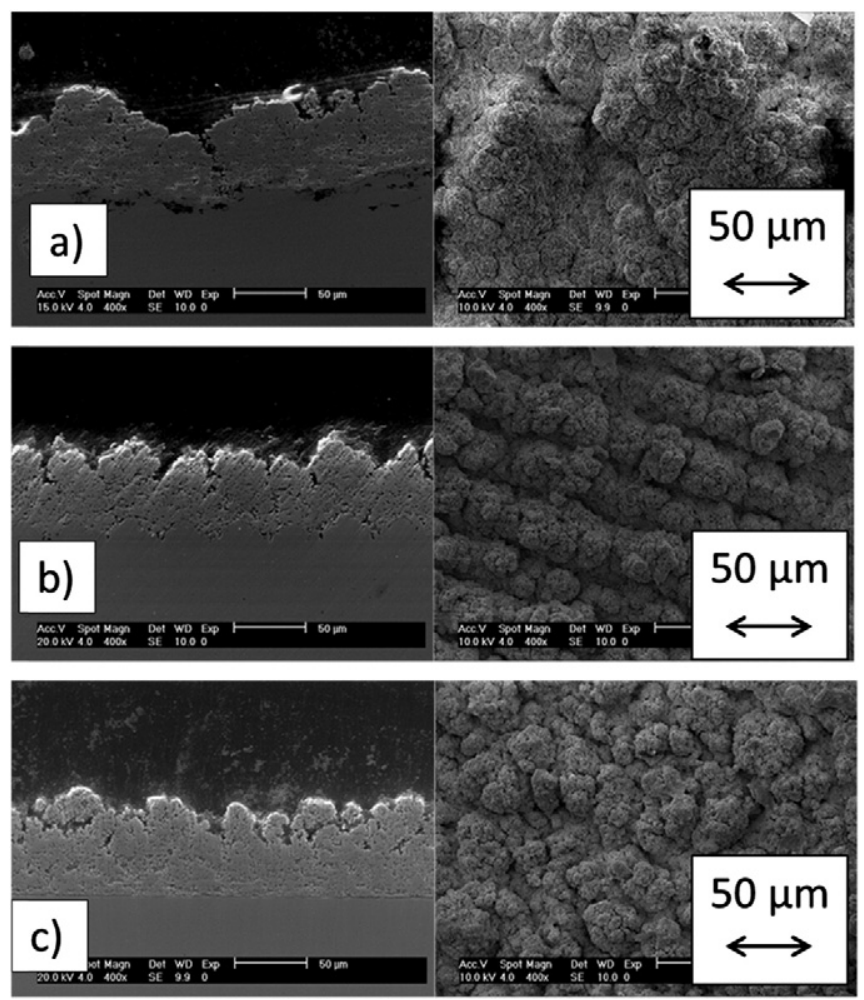

Fig. 6. SEM (secondary electrons) micrographs of cross-sections (left side) and surfaces (right side) of coatings suspension including $5 \mathrm{wt} . \%$ of $14 \mathrm{YSZ}$ solid phase sprayed using SG-100 torch onto substrates prepared by: (a) -sand blasting, sample ST51; (b)-laser treatment, sample ST52; (c)-grinding, sample ST53.

The fine solid particles arriving on the substrate may adhere to the substrate or move radially parallel to the substrate suspended in a working gas. The behavior of particles results from the equilibrium of two forces shown in Fig. 12, i.e.: (i) the force acting on a particle which can be assumed to be drag force, ${ }^{1} F_{\mathrm{D}}$, by the gas moving radially; and (ii) force of adhesion, $F_{\mathrm{A}}$, keeping the particle attached to the substrate. The drag force can be expressed under a simplified assumption that particles moves in Stokes regime as follows:

$F_{D}=3 \eta_{g} \pi d_{p}\left(v_{g}-v_{p}\right)$

in which $\eta_{\mathrm{g}}$ is the viscosity of gas acting on particle, $d_{\mathrm{p}}$ is the particle diameter, $v_{\mathrm{g}}$ is the velocity of gas equal to $v_{\mathrm{g}}=600 \mathrm{~m} / \mathrm{s}^{2}$ and $v_{\mathrm{p}}$ is the particle velocity. Supposing that the velocity of the particle is about a half of the velocity of gas, $v_{\mathrm{p}}=0.5 v_{\mathrm{g}}$, what corresponds roughly to the calculations made for fine hydroxyapatite particles in the numerical simulation presented elsewhere [20], and that the viscosity of working gas composed of plasma forming gases and products of suspension liquids evaporation is equal to $\eta_{\mathrm{g}}=6 \times 10^{-5} \mathrm{~kg} /(\mathrm{ms})$, the drag force for different particles diameters is represented in Fig. 13. The adhesion force, $F_{\mathrm{A}}$, can be approximated by a critical force measured at scratch test, i.e. the force applied when indenter reaches the coating's interface with the substrate. The values of critical force were measured to be in the range of 9 to more than $30 \mathrm{~N}$ in suspension plasma sprayed 8YSZ

\footnotetext{
${ }^{1}$ A more realistic model should take into account thermophoresis force [20]

2 The value corresponds to the working gas temperature of $3000 \mathrm{~K}$ calculated in the jet axis at the spray distance $40 \mathrm{~mm}$ and at the power input to the gas of $30 \mathrm{~kW}$ being lower than that used in the present study. More details are shown in the study [20].
}
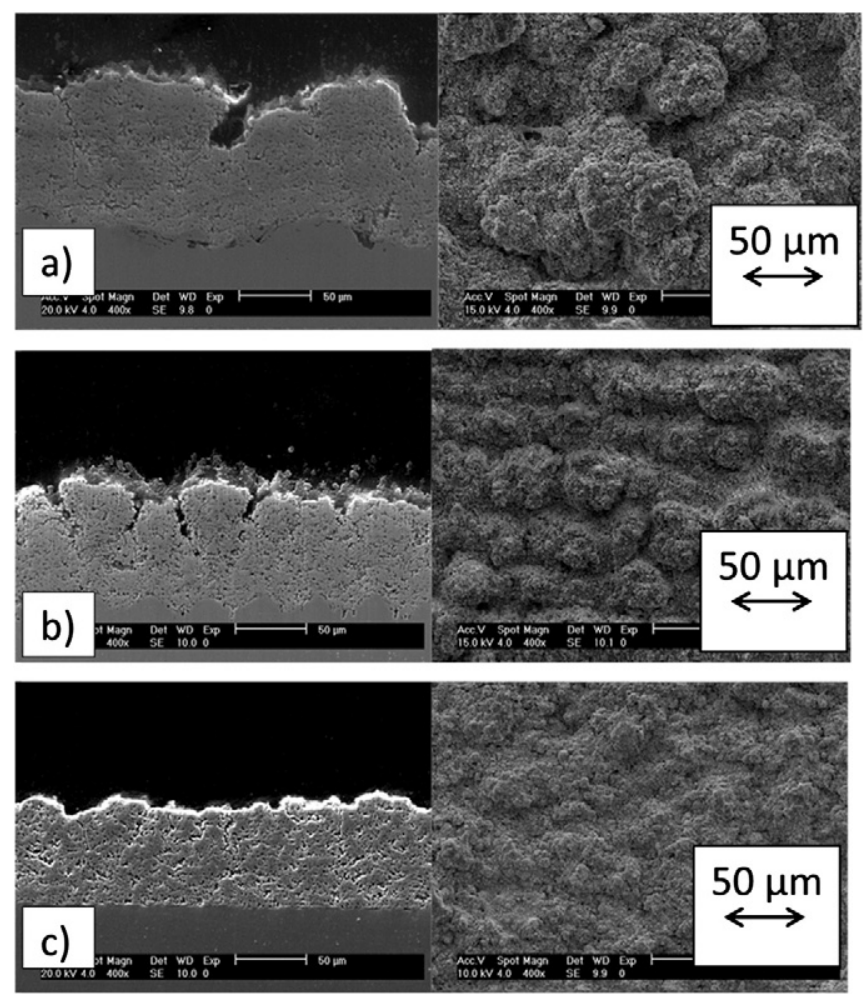

Fig. 7. SEM (secondary electrons) micrographs of cross-section (left side) and surfaces (right side) of coatings suspension including $10 \mathrm{wt}$.\% of 14YSZ solid phase sprayed using SG-100 torch onto substrates prepared by: (a)-sand blasting, sample ST101; (b)-laser treatment, sample ST102; (c)-grinding, sample ST103.
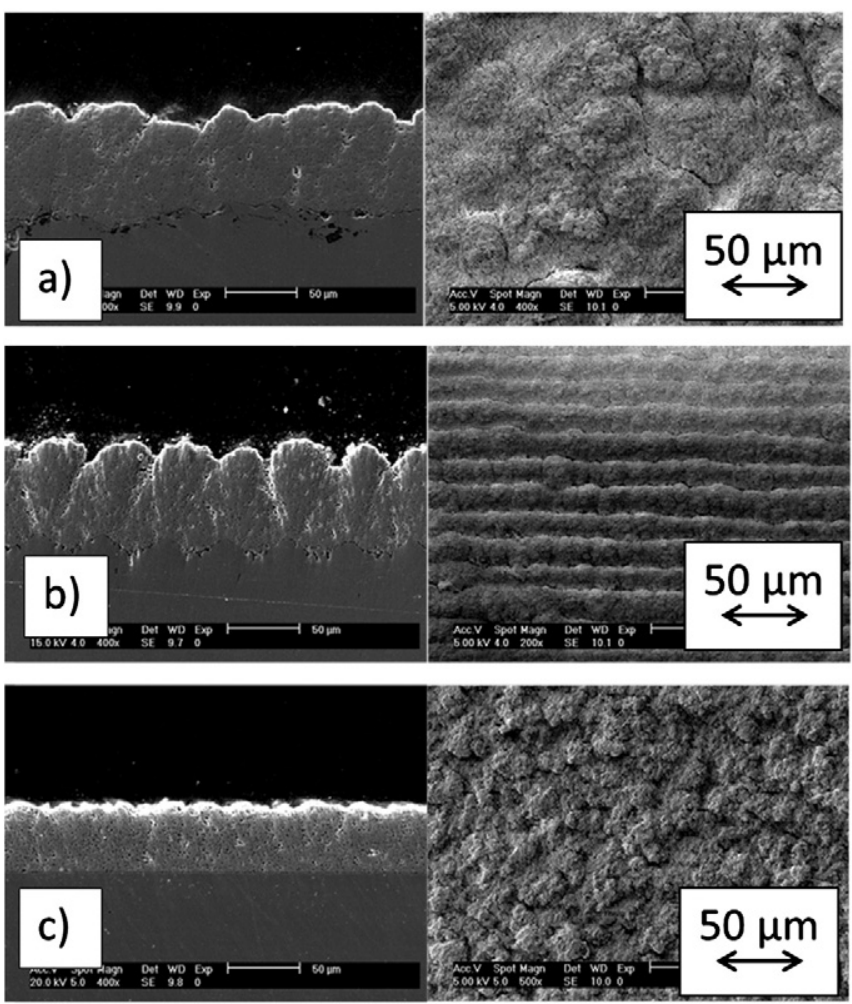

Fig. 8. SEM (secondary electrons) micrographs of cross-section (left side) and surfaces (right side) of coatings suspension including $10 \mathrm{wt} . \%$ of $14 \mathrm{YSZ}$ solid phase sprayed using Triplex torch onto substrates prepared by: (a)-sand blasting, sample TT101; (b)-laser treatment, sample TT102; (c)-grinding, sample TT103. 

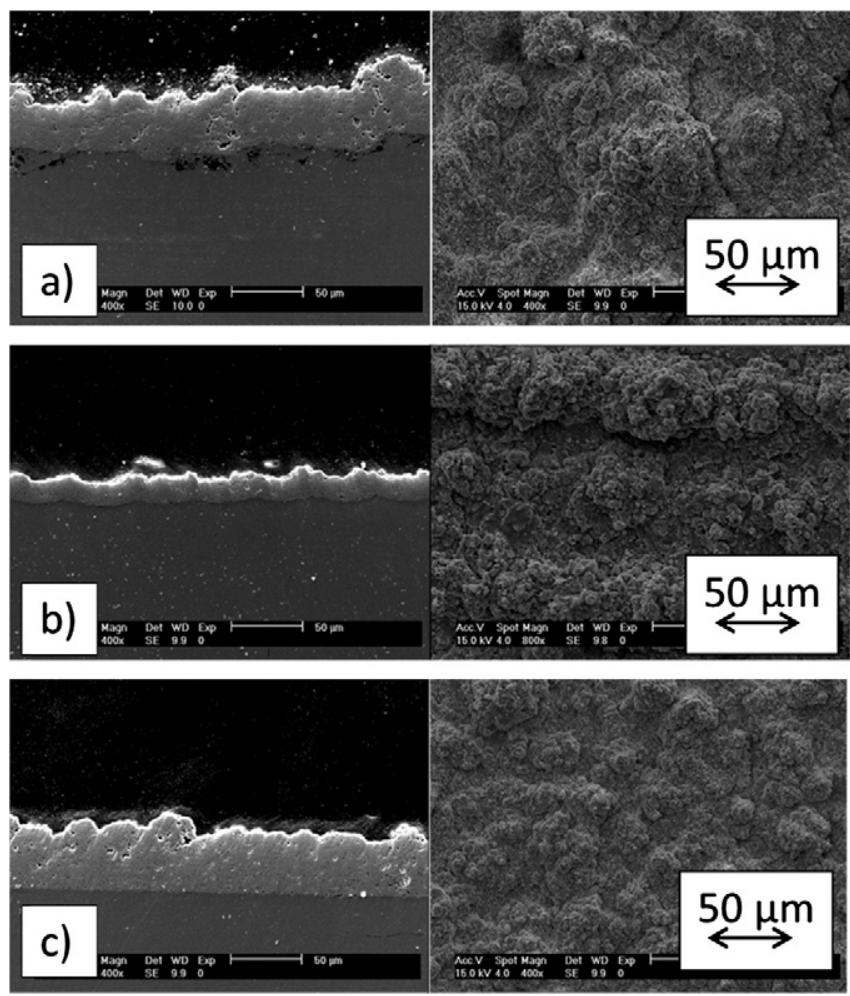

Fig. 9. SEM (secondary electrons) micrographs of cross-section (left side) and surfaces (right side) of coatings suspension including $2.5 \mathrm{wt}$.\% of YCSZ solid phase sprayed using SG-100 torch onto substrates prepared by: (a) -sand blasting, sample SC21; (b) -machining, sample SC22; (c)-grinding, sample SC23.

coatings [3] and 10 to $17 \mathrm{~N}$ for suspension plasma sprayed $\mathrm{TiO}_{2}$ coatings [21]. The very rough comparison of two forces acting on small particles shows that generally $F_{\mathrm{A}} \geq F_{\mathrm{D}}$ what means that the particles adhere to the substrate at impact. The explication of columnar microstructure formation may be given by the presence of small unmolten particles which remain on the periphery of the jet and arrive on the substrate with much lower velocity than the particles which has the trajectory in the middle of the jet (Fig. 14). These slow particles may be easily accelerated by the working gas moving radially with regard to the torch axis, parallel to the substrate. For these particles $F_{\mathrm{D}}>F_{\mathrm{A}}$ and they move parallel to the growing coating surface until they meet an irregularity on this surface to which they may adhere. Such irregularities were formed at substrate preparation by laser treatment, sand blasting or machining. The following torch passes bring new charge of particles contributing in forming the islands growing as the columns as shown in Fig. 15. However, a question remains how was it possible to form a columnar structure (sample ST23 shown in Fig. 5 c) on a grinded substrate having a smooth surface shown in Fig. 3b? The answer results from the superposition of many process parameters of the spray processes synthesized graphically in Fig. 16. The suspension used to spray this sample was having a small concentration of solids ( $2.5 \mathrm{wt} . \%$ ) and was well stabilized (zeta potential, $\zeta=82.5 \mathrm{mV}$ ) i.e. the fine solids were well separated. Moreover the SG-100 setup was having a large diameter of injector (ID = $0.5 \mathrm{~mm}$ ) and the droplets issuing from the injector were large too. These two factors may be synthesized by showing a large droplet with a few solids inside as shows it the right side of Fig. 16. The fine solids in large droplets were distant and some of them remain separated after evaporation of liquid from the droplet. These got molten and accelerated in the plasma jet and impacted on the substrate and adhered to it. The mechanism of adhesion of these small splats could have been their mechanical anchorage to the nano-irregularities of the smooth substrate. In that way the irregularities on the grinded surface became
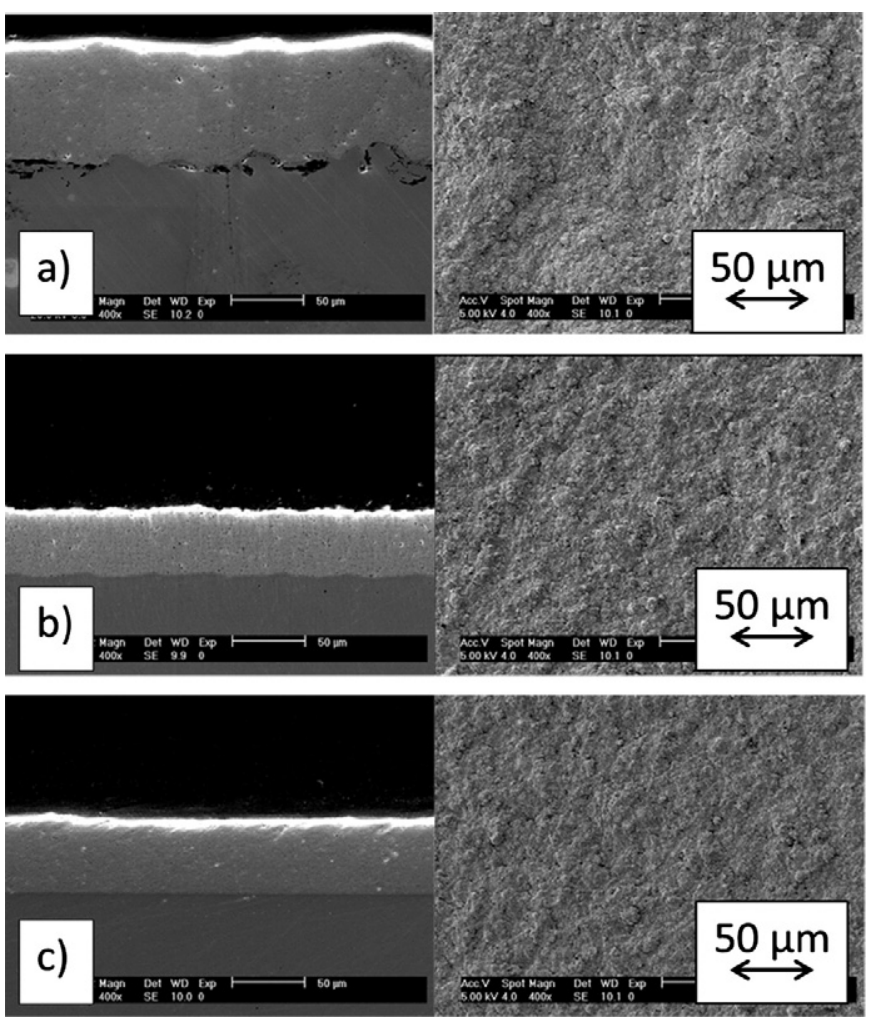

Fig. 10. SEM (secondary electrons) micrographs of cross-section (left side) and surfaces (right side) of coatings suspension including $10 \mathrm{wt}$.\% of YCSZ solid phase sprayed using Triplex torch onto substrates prepared by: (a)-sand blasting, sample TC101; (b)-machining, sample TC102; (c)-grinding, sample TC103.

greater and greater. Finally, their size was great enough to start the mechanism of columnar growth shown in Fig. 15.

\section{Conclusion}

The screening of some suspension plasma spraying process parameters influencing the formation of the columnar microstructure in zirconia coatings was carried out. The following experimental variables were used in 12 experimental runs: (i) powders in suspensions and their concentration; (ii), substrate preparation methods; and (iii) plasma spray equipment. The powders included yttria and ceria stabilized zirconia of composition $\mathrm{ZrO}_{2}+24$ wt.\% $\mathrm{CeO}_{2}+2.5$ wt.\% $\mathrm{Y}_{2} \mathrm{O}_{3}$ and $\mathrm{ZrO}_{2}+$ $14 \mathrm{wt} . \% \mathrm{Y}_{2} \mathrm{O}_{3}$. The coatings were deposited on the $304 \mathrm{~L}$ substrates having the surface prepared by: (i) grid blasting; (ii) grinding; (iii) turning; and (iv) laser treatment. The plasma torches used were: SG-100 and Triplex. The microstructure of the coatings was analyzed using scanning electron microscopy (SEM) and (FE-SEM) as well as the X-ray diffraction. Rietveld method was applied and enabled to determine that the 14YSZ samples crystallized as tetragonal zirconia and the YCSZ included major tetragonal phase and monoclinic zirconia as the minor one. Finally, the thermal conductivity of coatings was characterized up to $523 \mathrm{~K}$ with the use of laser flash method and it was found to be in the range of 0.6 to $1.1 \mathrm{~W} /(\mathrm{mK})$. The columnar microstructure was formed in the samples with both spray setups. Such microstructure was possible to form using fine 14YSZ powder suspension depending on the suspension concentration. Lower concentration promoted, generally, the formation of columns. The columnar microstructure when using coarse YCSZ powder was formed only with the laser treated substrate surface. The other substrate surface preparations methods resulting in the formation of the columnar microstructure were machining and turning. Surprisingly, it was found out that the spraying of such low concentration suspension as $2.5 \mathrm{wt} . \%$ of fine $14 \mathrm{YSZ}$ solids on a smooth, grinded substrate resulted 
a Thermal conductivity of 14YSZ coatings

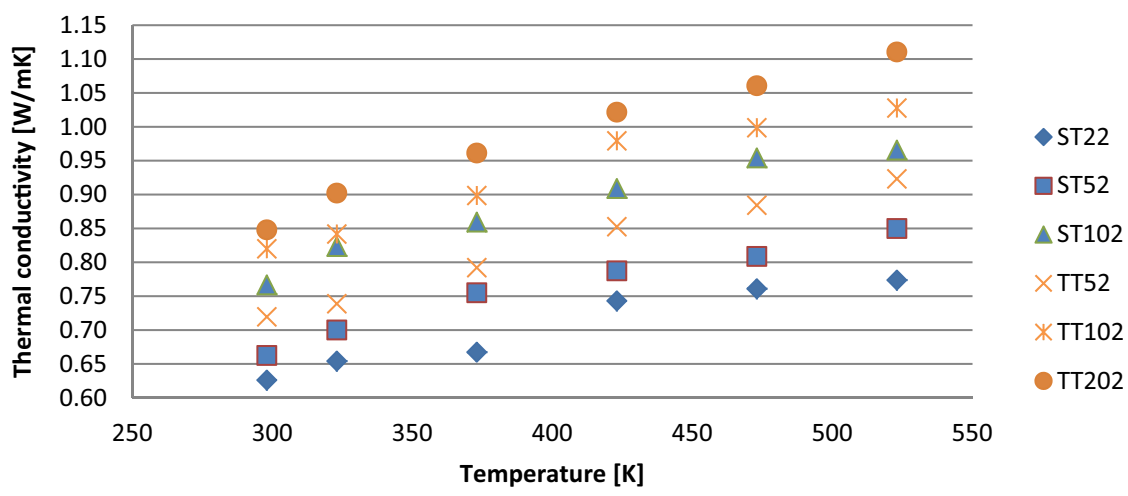

b Thermal conductivity of YCSZ coatings

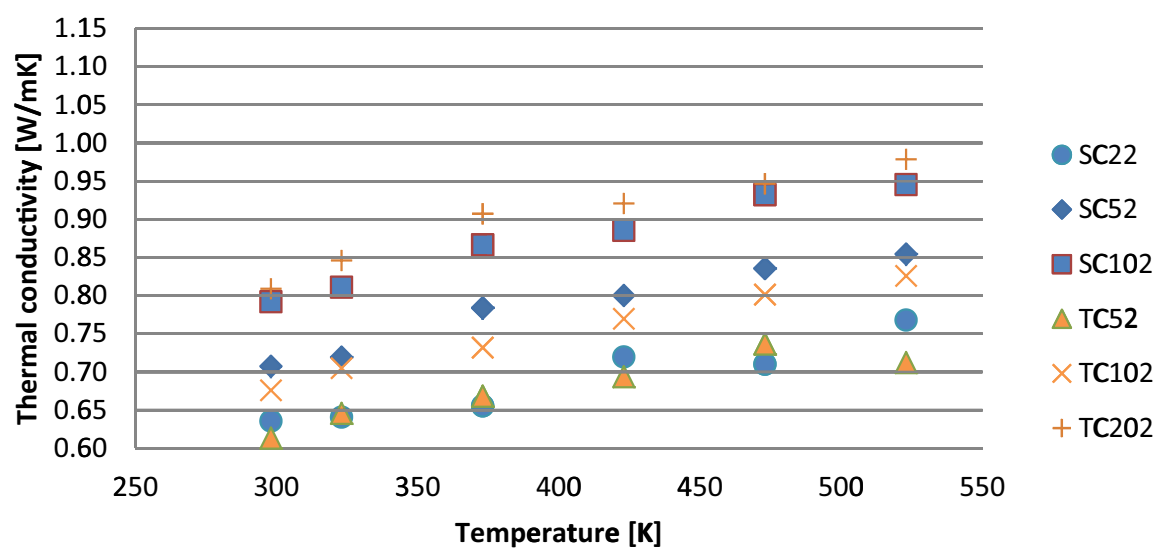

Fig. 11. Thermal conductivity of coatings sprayed using suspensions formulated with: (a)-14YSZ powder; (b)-YCSZ powder.

in the formation of the columnar microstructure. The simple model explaining the formation of the columnar microstructure was described. The future studies will concern the creation of more precise numerical model of interaction of fine solids with the working gas moving parallel to the substrate. The measurements of thermal conductivity at higher temperatures, thermal shock resistance and mechanical properties of the samples sprayed using optimized spray parameters should be also carried out.

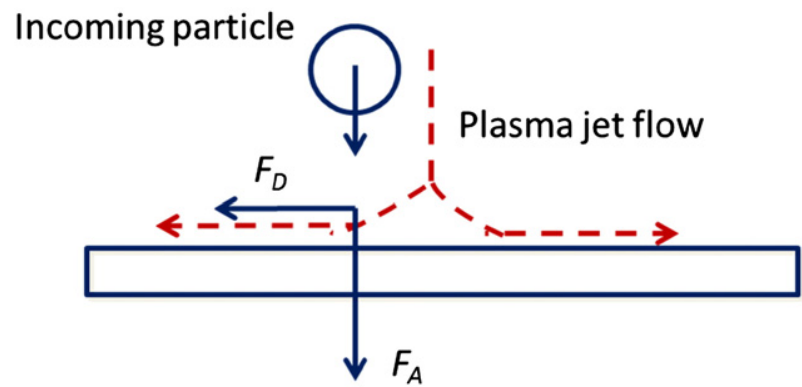

Fig. 12. Schematic representation of forces acting on a particles arriving on substrate or on previously deposited coating.

\section{Acknowledgments}

The help of David Jech, MSc Eng from Brno University of Technology in spray experiments and in coatings' characterization is thankfully

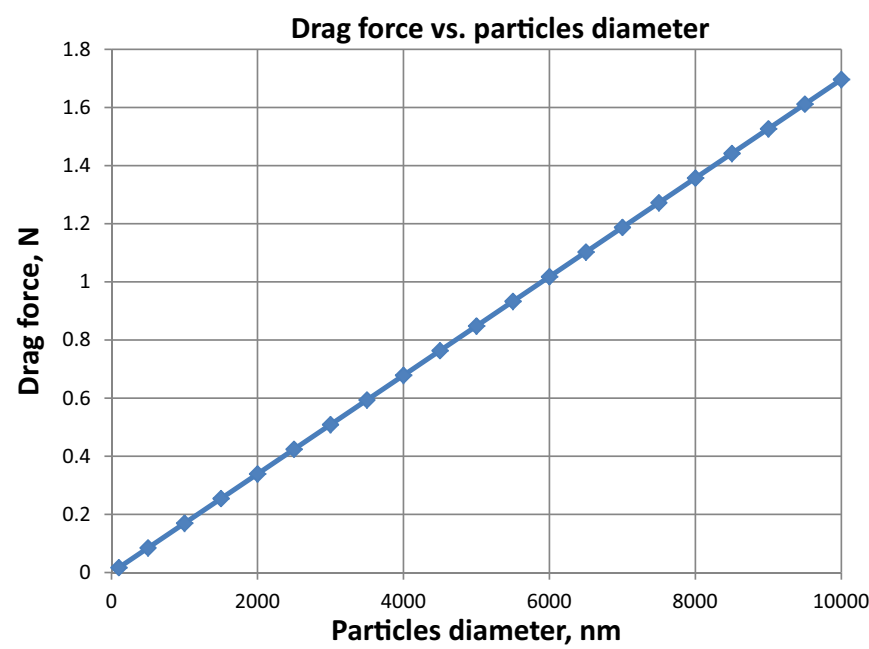

Fig. 13. Drag force vs. particles diameter for a simplified model developed following the data from our previous study [20]. 
a)

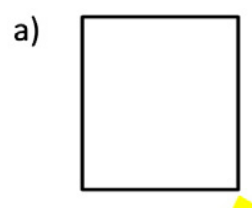

(2)



Fig. 14. Possible trajectories of droplets/particles during plasma spraying with the use of: (a) internal, injection (SG-100 torch); (b) external injection (Triplex torch).

Spray direction

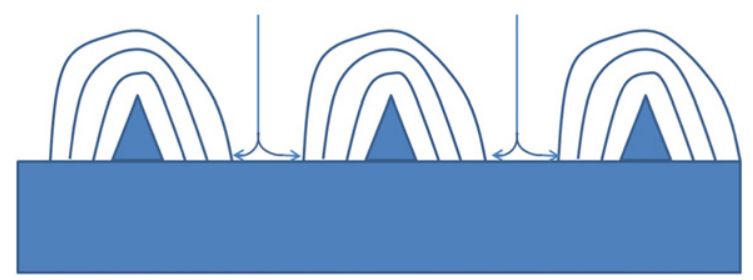

Substrate

Fig. 15. Mechanism of the columnar structure formation at suspension spraying on the roughened substrate having surface with many irregularities (inspired by [9]).

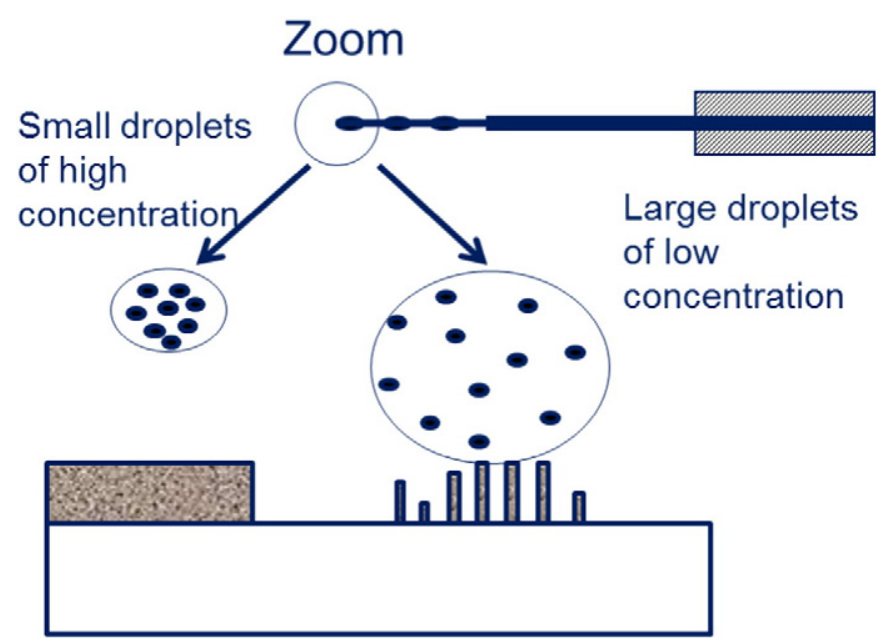

Fig. 16. Mechanism of the columnar structure formation in sample ST23 having a grinded surface as shown in Fig. 5c. The large droplet on the right side of the figure corresponds to the low concentration of a stable suspension (having great zeta potential).

acknowledged. Dr. Alain Denoirjean of SPCTS helped with the very useful discussions. The paper reviewers helped considerably in eliminating the paper's imperfections. The bilateral Polonium program financed by French government covered the travels fees of the researchers from
France and from Poland realized during this study. Drs Richard Mayet and Jean-Paul Laval helped in X-ray diffraction investigations.

\section{References}

[1] S. Kozerski, L. Pawłowski, R. Jaworski, F. Roudet, F. Petit, Surf. Coat. Technol. 204 (2010) 1380-1387.

[2] L. Łatka, S.B. Goryachev, S. Kozerski, L. Pawłowski, Materials 3 (7) (2010) 3845-3866.

[3] S. Kozerski, L. Łatka, L. Pawłowski, F. Cernuschi, F. Petit, C. Pierlot, H. Podlesak, J.-P. Laval, J. Eur. Ceram. Soc. 31 (2011) 2089-2098.

[4] K. VanEvery, M.J.M. Krane, R.W. Trice, W. Porter, H. Wang, M. Besser, D. Sordeletz, J. Ilavsky, J. Almer, Int. J. Appl. Ceram. Technol. 8 (6) (2011) 1382-1392.

[5] L. Łatka, A. Cattini, L. Pawłowski, S. Valette, B. Pateyron, J.-P. Lecompte, R. Kumar, A. Denoirjean, Surf. Coat. Technol. 208 (2012) 87-91.

[6] D.R. Clarke, M. Oechsner, N.P. Padture, MRS Bull. 37 (10) (2012) 891-897.

[7] R. Vaßen, M.O. Jarligo, T. Steinke, D.E. Mack, D. Stöver, Surf. Coat. Technol. 205 (2010) 938-942.

[8] R. Krishnamurthy, D.J. Srolovitz, Acta Mater. 57 (2009) 1035-1048.

[9] K. VanEvery, M.J.M. Krane, R.W. Trice, H. Wang, W. Porter, M. Besser, D. Sordelet, Jan Ilavsky, J. Almer, J. Therm. Spray Technol. 20 (4) (2011) 814-828.

[10] S. Gong, K. VanEvery, H. Wang, R.W. Trice, J. Eur. Ceram. Soc. 34 (2014) 1243-1253.

[11] N. Schlegel, S. Ebert, G. Mauer, R. Vaßen, ITSC 2014, Barcelona, Spain, DVS-Berichte, volume 302, ISBN: 978-3-87155-574-9, May 21-23, 2014, pp. 113-118.

[12] F. Cernuschi, P.G. Bison, S. Marinetti, P. Scardi, Acta Mater. 56 (16) (2008) 4477-4488.

[13] K.E. Wilkes, R.B. Dinwiddie, R.S. Graves, Thermal Conductivity 23, CRC Press, 1996.

[14] L.B. Pankratz, Thermodynamic Properties of Elements and Oxides, U. S. Bureau of Mines Bulletin, 1982. 672.

[15] Y. Takeda, H.Y. Tu, H. Sakaki, N. Imanishi, O. Yamamoto, M.B. Philips, N.M. Sommes, J. Electrochem. Soc. 144 (1997) 2810-2816.

[16] H. Miyazaki, J. Therm. Anal. Calorim. 98 (2009) 343-346.

[17] R.J. Jenkins, R.W. Westover, The Thermal Diffusivity of Stainless Steel Over the Temperature Range 20 C to 100 C, USNRDL TR-484, 1960. 1-13.

[18] A.P. Miller, A. Cezairliyan, High Temp. - High Press. 23 (1991) 205-214.

[19] W. Poessnecker, U. Gross, High Temp. - High Press. 34 (1) (2002) 1-8.

[20] B. Pateyron, L. Pawłowski, N. Calve, G. Delluc, A. Denoirjean, Surf. Coat. Technol. 214 (2013) 86-90.

[21] R. Jaworski, L. Pawłowski, F. Roudet, S. Kozerski, F. Petit, Surf. Coat. Technol. 202 (2008) 2644-2653. 